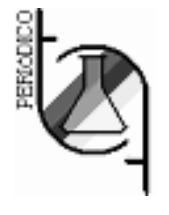

\author{
ESTUDO DO TRATAMENTO TÉRMICO DE AUSTÊMPERA EM \\ FERRO FUNDIDO NODULAR: ANÁLISE DAS PROPRIEDADES \\ MECÂNICAS E MICROESTRUTURAIS, SEGUNDO A NORMA \\ A897M STANDARD SPECIFICATION FOR AUSTEMPERED \\ DUCTILE IRON CASTINGS
}

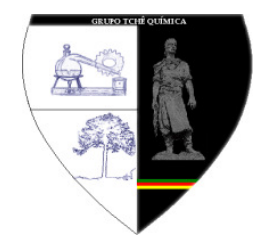

\title{
AUSTEMPERING HEAT TREATMENT STUDY OF CAST DUCTILE IRON: ANALYSIS OF MECHANICAL AND MICROSTRUCTURAL PROPERTIES, ACCORDING TO THE A897M STANDARD SPECIFICATIONS FOR AUSTEMPERED DUCTILE IRON CASTINGS
}

\author{
SCHIFINO, Alessandra Regina Machado ${ }^{{ }^{*}}$; SANT'ANNA, Felipe Riegel ${ }^{2}$; TRINDADE, \\ Alexandre Pinto ${ }^{3}$. \\ ${ }^{1}$ Universidade Federal do Rio Grande do Sul, Laboratório de Metalurgia Física, Av. Osvaldo Aranha, 99/610, \\ cep 23456-009, Porto Alegre - RS, Brasil \\ (fone: +55 $5133084251,+55513308$ 4246) \\ ${ }^{2}$ Fundimisa Fundição e Usinagem, Rua Giruá, 50, cep 98805-540, Santo Ângelo - RS, Brasil \\ (fone: +55 553313900 ) \\ ${ }^{3}$ Grefortec, Av. Getúlio Vargas, 3725, cep 93025-000, São Leopoldo - RS, Brasil \\ (fone: +55 513592 7111, +55 5199332 6444) \\ ${ }^{*}$ Autor correspondente \\ e-mail: alessandraschifino@gmail.com
}

Received 12 June 2017; received in revised form 17 August 2017; accepted 18 September 2017

\begin{abstract}
RESUMO
O objetivo deste trabalho foi realizar o desenvolvimento dos parâmetros de tratamento térmico, de uma liga em ferro fundido austemperado ASTM 897/A 897M - 1400/1100/1, para a produção de um suporte de molas de caminhão. O ferro fundido nodular austemperado, conhecido pela sigla na língua inglesa por ADI Austempered Ductile Iron - trata-se de uma classe de ferro fundido nodular que, após o tratamento térmico de austêmpera sofre um significativo aumento de suas propriedades mecânicas e tenacidade (Machado, 2007). Os ensaios mecânicos e metalográficos demonstraram a grande influência que o nível de micro-rechupes tem no alongamento e resistência mecânica do material. Geralmente os ensaios de tração demonstram elevado alongamento devido à mínima presença de micro-rechupes e segregações na matriz metálica do material, além da presença de austenita retida com alto carbono na matriz do ADI. Foram feitas análises a fim de identificar se foram alcançadas as propriedades mecânicas requeridas pela norma ASTM 897/A897M. Dentro desta norma, podem-se obter quatro graus, O grau de interesse neste estudo é a 1400/1100/1, que é o grau solicitado pela empresa, para que o suporte de molas de caminhão possa ser colocado em serviço. Os ensaios realizados foram de tração, Charpy e microscopia óptica.
\end{abstract}

Palavras-chave: Ferro fundido nodular; Tratamento térmico; Austêmpera; Norma A897M.

\begin{abstract}
The objective of this work was to develop heat treatment parameters of an austempered cast iron alloy ASTM 897 / A 897M - 1400/1100/1, aiming at the production of a truck spring support. The austempered nodular cast iron, known by the acronym ADI - Austempered Ductile Iron - is a class of nodular cast iron that, after austempered thermal treatment, increases significantly its mechanical properties and tenacity (Machado, 2007). Mechanical and metallographic tests demonstrated the great influence that the level of microshrinkage has on the elongation and mechanical resistance of the material. Generally, tensile tests demonstrate high elongation due to minimal presence of microshrinkage and segregations in the metallic matrix of the material, as well as to the presence of austenite with high carbon retained in the ADI matrix. Analyzes were performed to determine if the mechanical properties required by ASTM 897 / A897M were achieved. Within this standard, four
\end{abstract}


degrees can be obtained. The degree of interest in this study was $1400 / 1100 / 1$, which is the grade requested by the company, so that the truck spring support can be put into service. Tensile, Charpy and optical microscopy tests were carried out.

Keywords: Nodular cast iron; Heat treatment; Austempering; Standard A897M

\section{INTRODUÇÃO}

Em 1948 a BCIRA (British Cast Iron Research Association) e a INCA (International Nickel Company) anunciaram o desenvolvimento do ferro fundido nodular. Assim, também, iniciouse na década de 50 do século vinte o desenvolvimento do processo de austêmpera de ferro fundido nodular (Hayryen, 2002).

A estrutura resultante da austêmpera do ferro fundido nodular, foi denominada por Kovacs (1990) como Ausferrita. A austêmpera do ferro fundido nodular é o tratamento térmico que propicia a melhor combinação de propriedades mecânicas (resistência mecânica, tenacidade e resistência ao desgaste) se comparado a outros tratamentos térmicos aplicados no material. Portanto, desde a metade da década de 1970, o material vem sendo aplicado na Finlândia e nos Estados Unidos, inicialmente em engrenagens em geral e em sistemas de engrenagens na indústria automobilística.

Atualmente o ferro fundido austemperado encontra-se com uma produção estimada de 181.436 (Keough, 2002) toneladas anuais, produzidas em todos os continentes.

O ADI, possui uma ótima relação entre a resistência mecânica e densidade, aliada a uma boa resistência à fadiga (Hayrynen et al., 2002). Adicionalmente, a densidade do ferro fundido austemperado é aproximadamente 10\% menor do que a densidade do aço. Adicionalmente, o ADI apresenta uma resistência mecânica três vezes maior e duas vezes e meia a densidade do alumínio; assim, no mesmo sentido que o aço, o ADI pode substituir ligas de alumínio com o mesmo ou alguma redução de peso, porém com substancial redução de custos (Hayrynen, et al., 2002; Röhrig, 2002).

Durante a solidificação do ferro fundido nodular, a fase mais desfavorável para nuclear e crescer é a grafita, devido ao mecanismo de crescimento ser divorciado (Santos, 1998). Isto significa que a grafita, inicialmente, nucleará no líquido e será rapidamente envolta por uma capa de austenita. Segundo relato por Jiyang (1993), se o envolvimento da capa de austenita no nódulo for rápido, haverá a formação de nódulos pequenos e redondos devido à dificuldade da entrada do carbono proveniente do líquido. Entretanto, se o envolvimento da capa de austenita for lento, haverá a presença de veios de líquido que favorecerão o carbono do líquido chegar mais rápido ao nódulo, mas somente em determinados pontos, 0 que irá gerar 0 crescimento irregular dos nódulos (grafita degenerada). Assim, sem o envolvimento do nódulo pela capa de austenita, este se degenera em muitas direções. As grafitas degeneradas são responsáveis pela redução das propriedades mecânicas no estado bruto de fusão e, por consequência, após a austêmpera do material (Santos, 1998).

A fase inicial, gerada na solidificação do ferro fundido nodular é a austenita, que nucleou abaixo da linha liquidus; onde o teor de carbono dissolvido na austenita e no líquido remanescente é alto. O carbono equivalente será o do eutético estável e a nucleação e o crescimento das células ocorrem com a liberação do calor latente que irá favorecer a recalescência, que é o aumento da temperatura do líquido para iniciar a reação eutética (Lussoli, 2003).

Adicionalmente, a utilização combinada de ambos os elementos ( $\mathrm{S}$ e O) através de uma pós-inoculação, é uma nova abordagem que tem sido utilizada combinada com a utilização simultânea de cério e cálcio, para obterem-se melhoras significativas na eficiência da nucleação em todo o período de solidificação do metal (Skaland, 2002). Portanto, nos ferros fundidos nodulares (precursores dos ADI) a inoculação possibilita elevar o número de nódulos, aumentar a quantidade de ferrita presente na microestrutura, obter melhor nodularidade da grafita e diminuir a tendência à formação de microporosidades e carbonetos (Santos, 1991).

Define-se austêmpera, como um tratamento isotérmico, que aplicado ao ferro fundido nodular, incrementa as propriedades mecânicas e a tenacidade. Em termos gerais, o processo consiste do aquecimento do material para completa austenitização em temperaturas 
entre $850^{\circ} \mathrm{C}$ a $950 \stackrel{\circ}{\circ} \mathrm{C}$. O material é mantido nestes níveis de temperatura de tratamento, até que a matriz do ferro fundido nodular, seja uniformemente composta de austenita saturada com carbono em equilíbrio. Então, segue-se rápido resfriamento até a temperatura de austêmpera, usualmente entre $230^{\circ} \mathrm{C}$ a $400^{\circ} \mathrm{C}$, que será isotermicamente mantida até que a transformação da matriz do ferro fundido nodular, torne-se completamente ausferrítica (Hayrynen, et al., 2002).

A estrutura formada pela ferrita, austenita e carbonetos precipitados, tem a energia livre menor do que a estrutura composta de austenita com alto teor de carbono $\left(\mathrm{Y}_{\mathrm{H}}\right)$ e ferrita acicular (a). Se o tempo de manutenção do material na etapa II for muito longo, a austenita tende a desaparecer e a ferrita acicular e os carbonetos formam uma estrutura ainda mais estável denominada bainita. A estrutura bainítica, é indesejável para o nodular austemperado, por ser deletéria as propriedades mecânicas do material, principalmente, para a tenacidade e a ductilidade do ADI (Viáfara e Vélez, 2005).

Deste modo, o processo de austêmpera é dividido em dois estágios; o final do primeiro estágio corresponde à maximização da fração de ferrita acicular ( $\alpha$ ) e austenita com alto teor de carbono $\left(\mathrm{Y}_{\mathrm{H}}\right)$ e o segundo estágio corresponde ao início da precipitação de carbonetos. O intervalo de tempo entre os dois estágios, é denominado de janela de processo de tratamento térmico de austêmpera (Yescas, et al., 2001).

Segundo Thomson (2000), a temperatura e o tempo de austenitização são fatores críticos para a produção de ferro fundido austemperado, pois determinarão a quantidade de carbono contido na matriz austenítica, usualmente, entre temperaturas de 850 a $950{ }^{\circ} \mathrm{C}$, a variação de temperatura deve ser de $\pm 10^{\circ} \mathrm{C}$, (Carmo, 2001; Restrepo e González, 2004) para a subsequente transformação isotérmica da matriz austenítica para ausferrítica.

Em termos da quantidade de carbono na austenita retida (CY), considerações termodinâmicas indicam que para uma dada condição de austêmpera, Cy é independente da temperatura de austenitização do material (Bahmani, 1997; Putatunda e Gadicherla, 1999). Entretanto, uma redução na temperatura de austenitização, aumenta a força motriz para a redução do primeiro estágio, sem ter um efeito significativo no segundo estágio de austêmpera, ou seja, expande a amplitude da janela de processo. No mesmo sentido, Putatunda e Gadicherla (1999) relatam que a força motriz para a reação do primeiro estágio decresce com o incremento da temperatura de austenitização e concluem que em altas temperaturas de austenitização a austenita torna-se mais estável; isto diminui a nucleação de ferrita (durante a operação de austêmpera) e reduz a cinética do primeiro estágio. No que concerne a quantidade de austenita estabilizada pelo alto teor de carbono $\left(\mathrm{Y}_{\mathrm{H}}\right)$, a mesma é uma função diretamente proporcional ao aumento da temperatura de austenitização, no intervalo usual de austenitização do material entre 850 a $950^{\circ} \mathrm{C}$.

Decorrida a austenitização, o material será resfriado até a temperatura de austêmpera $\left(T_{A}\right), \quad 0$ tratamento isotérmico, permitirá a supersaturação da austenita com carbono para formação da estrutura ausferrítica.

A temperatura de austêmpera varia entre 230 e $400{ }^{\circ} \mathrm{C}$, com tolerância recomendada de \pm $8 \stackrel{\circ}{ } \mathrm{C}$ e o tempo de manutenção em temperatura entre 30 e 240 minutos. A escolha da temperatura de austêmpera determinará o grau de propriedades mecânicas que o material terá, ou seja, baixas temperaturas de austêmpera $\left(T_{A}\right.$ $\leq 350^{\circ} \mathrm{C}$ ) produzirão maiores valores de resistência mecânica, limite de escoamento e dureza. Por outro lado, altas temperaturas de austêmpera, produzirão maiores valores de alongamento, energia absorvida ao impacto e resistência à fadiga (Hayrynen, 2002; Carmo, 2001; Hayrynen, 1995; Campos-Cambranis, 1998).

Todas estas variáveis terão resultado direto nas propriedades do ferro fundido ausferrítico. A austêmpera é um tratamento isotérmico, que aplicado ao ferro fundido nodular, incrementa as propriedades mecânicas e a tenacidade. $O$ processo consiste em aquecer 0 material para completa austenitização em temperaturas entre 850 e $950^{\circ} \mathrm{C}$. O material é mantido nestes níveis de temperatura de tratamento, até que a matriz do ferro fundido nodular seja uniformemente composta de austenita saturada com carbono em equilíbrio. Então, em seguida é realizado um rápido resfriamento até a temperatura de austêmpera, usualmente entre 230 e $400^{\circ} \mathrm{C}$.

\section{MATERIAIS E MÉTODOS}

Para a realização deste estudo foi realizado o tratamento térmico de austêmpera 
em forno de poço (banho de sal), onde duas cargas idênticas foram realizadas, na empresa GREFORTEC, utilizando-se os parâmetros da Tabela 1.

Foram utilizados suportes para imersão das peças, com duas unidades em cada. Após a realização do tratamento térmico, as peças foram enviadas ao SENAI CETEMP-LABORATORIO DE ENSAIOS E CALIBRAÇÂO/São Leopoldo, RS, para a realização da usinagem. Efetuandose assim os ensaios de tração, Charpy e dureza Brinell.

\subsection{Ensaios de Tração}

Os ensaios foram realizados através da medição do diâmetro inicial da amostra, traçando o comprimento inicial padrão e assim sendo colocado nas garras da máquina de ensaio, realizando-se o ensaio de tração. Utilizou-se: máquina universal de ensaios de tração, paquímetro e termohigrômetro, todos os equipamentos certificados pelo próprio SENAICETEMP/São Leopoldo, RS. Seguindo a norma ABNT NBR ISO 6892 - 1. Apresentados na Tabela 2.

\subsection{Ensaios Charpy e Dureza Brinell}

Os ensaios foram realizados através da medição dos lados e do comprimento da amostra na posição do ensaio, obtendo assim a energia absorvida no impacto. As medidas são apresentadas nas Tabelas 3, 4 e 5. Utilizou-se: máquina de ensaios de impacto e termohigrômetro, todos os equipamentos certificados pelo próprio SENAI-CETEMP/São Leopoldo, RS. Seguindo a norma ASTM e 23. As durezas superficiais foram feitas na empresa GREFORTEC no duromêtro PAN701 da marca OPITI MESS calibrado em 17 de abril de 2014.

\subsection{Análises Metalográficas}

Os ensaios foram realizados na empresa GREFORTEC, utilizando microscópio óptico da marca OPTI MESS. Os corpos de prova foram preparados utilizando-se as amostras já usinadas anteriormente, as mesmas foram lixadas em lixas com granulometria 200, 400, 600 e depois polidas com pasta de alumina e realizado 0 ataque com reagente Nital $2 \%$ (2ml $\mathrm{HNO} 3+$ 98ml Álcool Etílico), segundo a norma ASTM E407 - 07(2015) e1.

\section{RESULTADOS E DISCUSSÃO}

Nessa etapa do estudo, e com base nos objetivos propostos são apresentados os resultados de forma comparativa da norma A897M Standard Specification for Austempered Ductile Iron Castings com o material tratado pela GREFORTEC. Parâmetros da norma apresentados na Tabela 6.

\subsection{Ensaios de Tração}

A Tabela 7 demonstra que os resultados para as mostras 1, 2 e 3 não alcançam exatamente o valor exigido pela norma A897M grau 1400/1100/1, porém o resultado é muito próximo, sendo então considerado como resultado positivo no tratamento térmico de austêmpera. Entretanto, as análises metalográficas destas amostras, representadas nas Figuras 6 e 7, indicam ocorrência de microporosidades, que afetam de modo deletério o alongamento e a resistência mecânica do material austemperado. Portanto, possivelmente outros parâmetros de tratamento térmico atingiram as especificações de propriedades mecânicas do material, outro ponto importante é averiguar se as porosidades estão presentes na matriz, pois podem ser causa de fragilização.

A seguir, os resultados obtidos nos ensaios de tração de forma gráfica, para que se possa comparar as propriedades mecânicas obtidas nos testes com a norma. Assim, as Figuras 1, 2 e 3 apresentam os resultados da resistência mecânica, em função do alongamento e o limite de escoamento em função da resistência mecânica e do alongamento. A linha contínua representa os requisitos mínimos da norma ASTM A897 para alguns graus conhecidos de austêmpera; portanto, os pontos acima da linha cheia, amostras 2 e 3, representa que foram atingidos os requisitos da norma, e os pontos abaixo da linha contínua, amostra, representa a amostra que não atingiu os requisitos mínimos. 


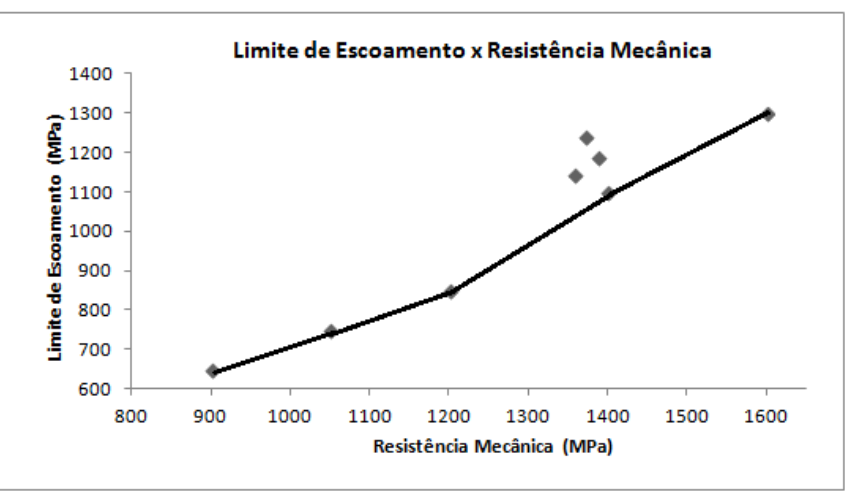

Figura 1. Resistência mecânica em função do alongamento, onde os pontos acima da linha contínua e após $1 \%$ de alongamento, atingiram

o grau 1400/1100/1 de austêmpera.

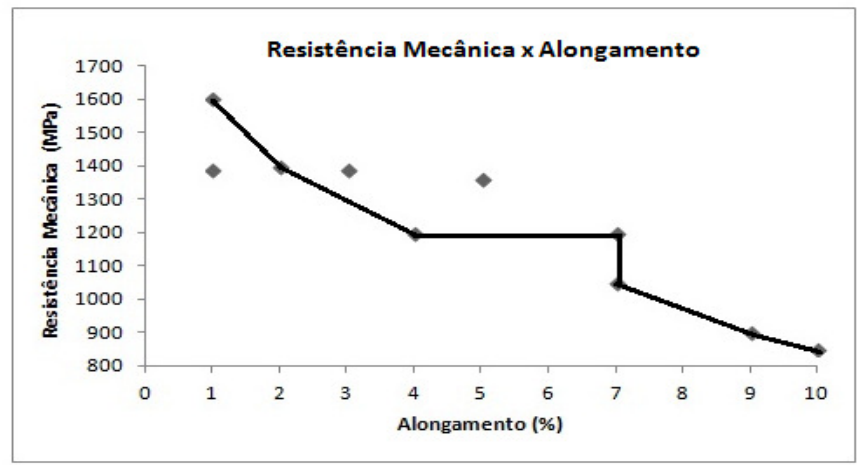

Figura 2. Limite de escoamento em função da resistência mecânica, onde os pontos acima da linha contínua e após $1350 \mathrm{MPa}$ de resistência mecânica, atingiram o grau 1400/1100/1 austêmpera.

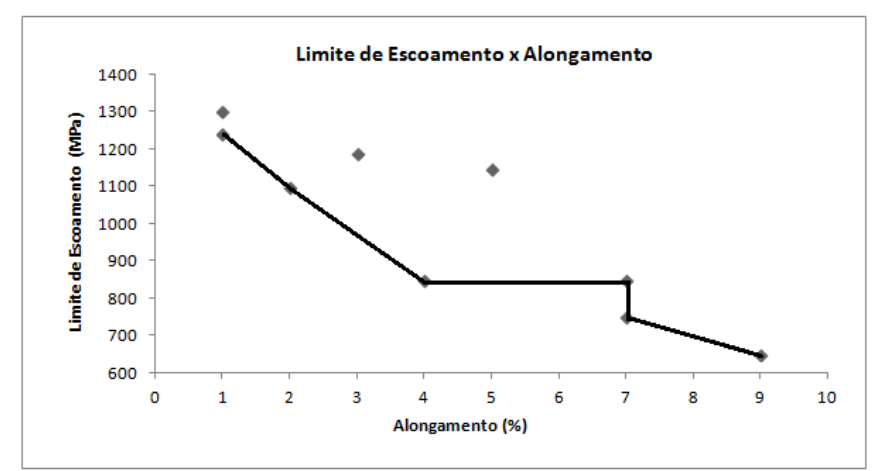

Figura 3. Limite de escoamento em função do alongamento, onde pontos acima da linha contínua e após o limite de escoamento de $1 \%$, atingiram o grau 1400/1100/1 de austêmpera.

\subsection{Ensaios de Impacto - Charpy.}

Os resultados do teste de impacto Charpy para as amostras 2 e 3 , foram satisfatórios, pois alcançaram a energia mínima de $35 \mathrm{~J}$, que a norma especifica para o teste, este resultado foi atribuído ao nível de austenita retida na matriz do material, porém a amostra 1 não alcançou o limite mínimo, pois sua microestrutura não apresentava a quantidade ideal de austenita retida, sendo esta a microestrutura que concede dureza e resistência mecânica a peça. As Tabelas 8, 9 e 10 apresentam os resultados obtidos, e a Figura 4, a energia absorvida em função da dureza de cada peça.

Para estar de acordo com a norma A897M grau 1400/1100/1 os dois itens devem ser afirmativos, constatando-se assim que a amostra 2 e 3 estão de acordo e a amostra 1 está muito próxima do valor de 35J. Dados apresentados na Tabela 11.

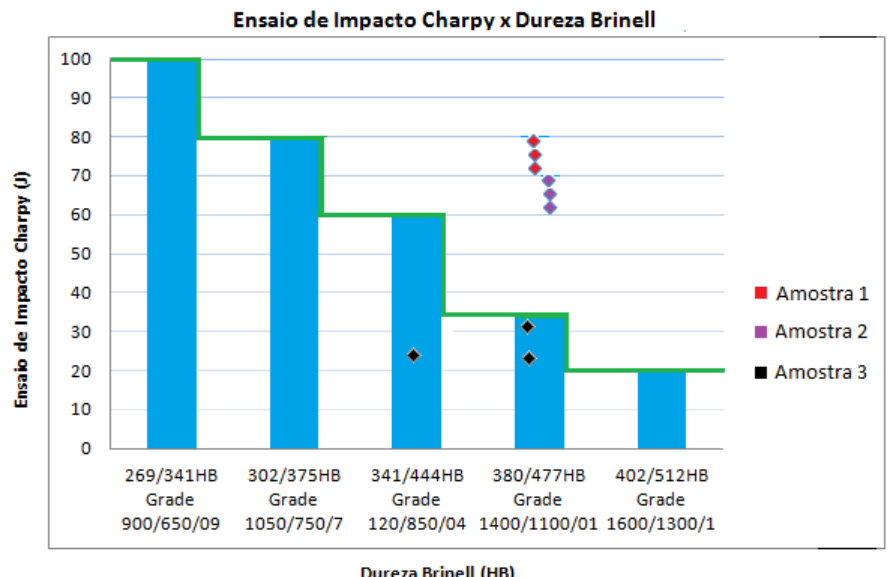

Figura 4. Ensaio de Impacto Charpy em função da dureza Brinell, onde os pontos coloridos indicam os valores da energia absorvida no ensaio de Charpy e seu respectivo grau, conforme a norma ASTM A897. Sendo a linha verde o valor mínimo de energia absorvida que deve ser alcançado em cada grau.

\subsection{Análises Metalográficas}

As microestruturas das 3 amostras analisadas apresentam características semelhantes, pois os resultados alcançados obtiveram boa repetitividade. As análises metalográficas do ADI apresentaram estrutura austferrítica. Como pode ser visto na figura 5 esta estrutura é composta por austenita retida estabilizada por carbono que confere ductilidade ao material e por ferrita acicular que é responsável pela resistência mecânica. A microestrutura mesclada demonstra que o tempo de austêmpera próximo aos nódulos de grafita é mais longo do que a meia distância deles. 
Observa-se na Figura 5, que a baixa contagem de nódulos, favorece a segregação de elementos de liga tais como manganês e molibdênio. A literatura recomenda no máximo $1 \%$ de porosidades para não haver comprometimento do alongamento e resistência mecânica do material.

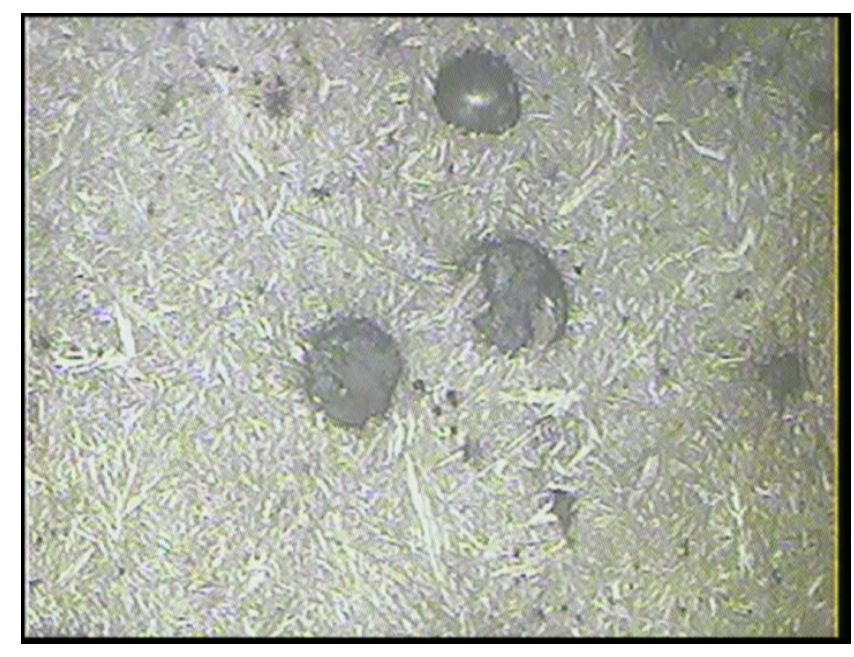

Figura 5. Microestrutura ADI, composta de ferrita acicular (escura) e austenita retida (clara). Aumento 400x. Ataque Nital 2\%.

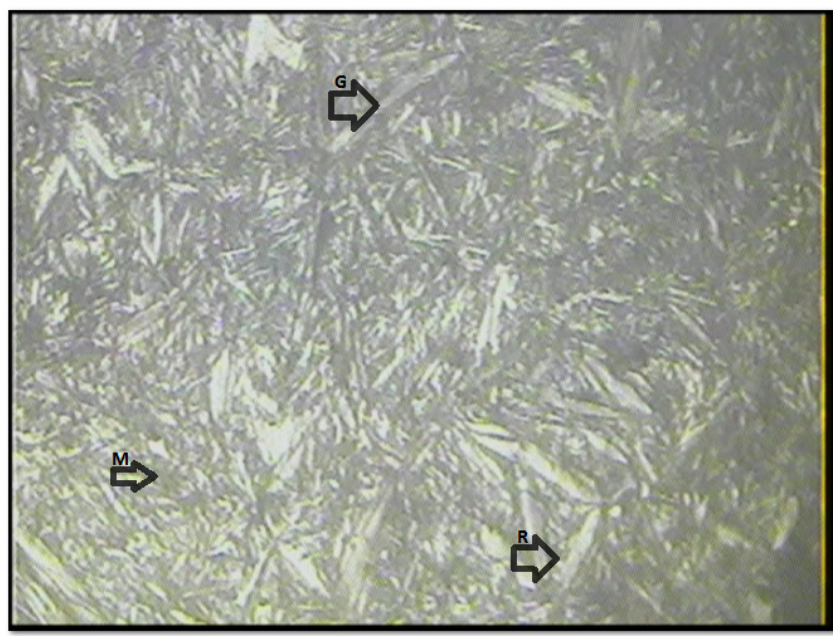

Figura 6. Microestrutura ADI anterior, porém, com maior aumento, composta de estrutura mesclada com agulhas de ferrita refinadas $(R)$, grosseiras (G), massivas (M) e austenita retida. Aumento 1000x. Nital 2\%.

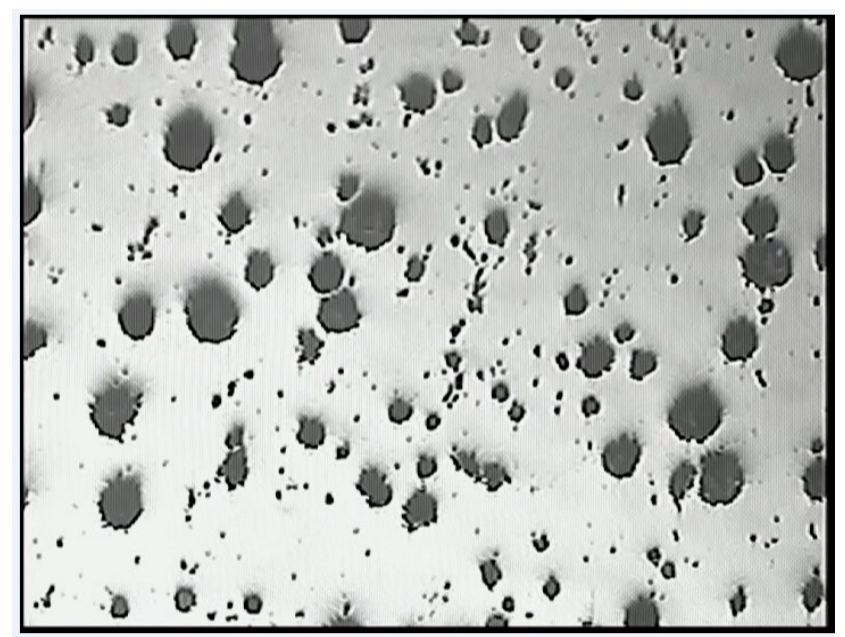

Figura 7. Microestrutura do ferro fundido base, onde se observa a presença de micro-rechupes. Aumento: 100x. Ataque: Sem ataque.

\section{CONCLUSÕES:}

No ensaio Charpy, os resultados alcançados foram satisfatórios. No caso da dureza Brinell existe uma homogeneidade dos valores, não sendo afetada pelos microrechupes. Já no ensaio de tração, para se alcançar os padrões especificados pela norma A897M grau 1400/1100/1, foi usado um ensaio sem entalhe, pois assim o entalhe não dissipa a energia que deveria ser absorvida pelo corpo de prova. Sendo assim, apesar dos micro-rechupes em algumas das amostras, as mesmas se encontram dentro dos valores especificados pela norma para o limite de escoamento com uma pequena variação para baixo da resistência a tração, não significativa, estando também nas condições exigidas pela norma. Alterações na composição química e maior refino dos nódulos de grafita poderão influenciar na melhoria das propriedades mecânicas e no processo de tratamento térmico do material.

\section{REFERÊNCIAS:}

1. American Society for Testing Materials ASTM 897/A 897 - 06, Standard Specification for Austempered Ductile Iron Castigs. Reapproved 2011.

2. Machado, M.A.; Dissertação de Mestrado, Universidade Federal do Rio Grande do Sul, Brasil, 2007.

3. Hayrynen, K.L.; The Production of Austempered Ductile Iron (ADI), World Conference on ADI, Louisville, Kentucky, EUA, 2002. 
4. Kovacs, B.V.; Modern Casting, 1990, 80.

5. Hayrynen, K.L.; Branderberg, K.R., Keough, J.R.; AFSTrans, 2002, 02-084.

6. Keough, J.R.; ADI Developments in North America - Revisited 2002, World Conference on ADI, Louisville, Kentucky, EUA, 2002.

7. Röhrig, K.; Europäische ADI - Entwicklungs - konferenz - Eigenschaften, Bauteil entwicklung ung Anwendungen, Hannover Messe Industrie, 2002.

8. Santos, A.B.S.; Congresso Anual da Associação Brasileira de metalurgia e materiais - ABM, Belo Horizonte, Brasil, 1998.

9. Jiyang et al.; Fundição \& Serviços, ago. Set., 1993.

10. Lussoli, R.J.; Dissertação de Mestrado, Universidade Federal de Santa Catarina, Brasil, 2003.

11. Skaland, T.; Ductile Iron Shrinkage Control Through Graphite Nucleation and Growth, 2002.

12. Santos, A.B.S.; Castelo Branco, C.H.; Metalurgia dos Ferros Fundidos Cinzentos e Nodulares; IPT: São Paulo, 1991.

13. Carmo, D.J.; Ferro Fundido Austemperado ADI, Senai, Belo Horizonte, Brasil, 2001.

14. Viáfara, C.; Vélez, J.M.; Ingeniería y Ciencia, 2005, 1, 2.

15. Yescas, M.A.; Bhadeshia, H.K.D.H.; Mackay, D.J.; Materials Science and Engineering, 2001, A311.

16. Bahmani, M.; Elliott, R.; Varahram, N.; Journal of Materials Science, 1997, 32.

17. Thompson, R.C.; James, J.S.; Putman, D.C.; Materials Science and Technology, 2000, 16.

18. Putatunda, S.K.; Gadicherla, P.K.; Material Science and Engineering, 1999.

19. Restrepo, H.S.; González, J.O.; Revista Universidad EAFIT, 2004, 134.

20. Hayrynen, K.; Modern Casting, 1995.

21. Campos-Cambranis, R.E.; Scripta Materialia, 1998, 38, 8.

22. Associação Brasileira de Normas Técnicas. NBR ISO 6892 - 1. Materiais metálicos Ensaio de Tração - Parte 1: Método de ensaio à temperatura ambiente. 2013.

23. American Society for Testing Materials Standard Test Methods for Notched Bar Impact Testing of Metallic Materials.2016.

24. American Society for Testing Materials Standard Practice for Microetching Metals and Alloys. 2015. 
Tabela 1. Parâmetros Tratamento Térmico GREFOREC

\begin{tabular}{c|c|c|c}
\hline Tratamento & Pré Aquecimento & Austeniti-zação & Austêm-pera \\
\hline Temperatura & $450^{\circ} \mathrm{C}$ & $900^{\circ} \mathrm{C}$ & $270^{\circ} \mathrm{C}$ \\
\hline Tempo & - & $60 \mathrm{~min}$ & $60 \mathrm{~min}$ \\
\hline
\end{tabular}

Tabela 2. Dimensões Corpo de Prova Ensaio de Tração

\begin{tabular}{c|c|c|c}
\hline Amostra & $\mathbf{1}$ & $\mathbf{2}$ & $\mathbf{3}$ \\
\hline Formato da Amostra & Cilíndrico & Cilíndrico & Cilíndrico \\
\hline Material da Amostra & ADI & ADI & ADI \\
\hline $\begin{array}{c}\text { Diâmetro Inicial da } \\
\text { Amostra }\end{array}$ & $12,41 \mathrm{~mm}$ & $12,39 \mathrm{~mm}$ & $12,41 \mathrm{~mm}$ \\
\hline $\begin{array}{c}\text { Diâmetro final da Amostra } \\
\text { Comprimento Inicial da } \\
\text { Amostra }\end{array}$ & $12,37 \mathrm{~mm}$ & $12,21 \mathrm{~mm}$ & $12,06 \mathrm{~mm}$ \\
\hline $\begin{array}{c}\text { Comprimento Final da } \\
\text { Amostra }\end{array}$ & $50,00 \mathrm{~mm}$ & $50,00 \mathrm{~mm}$ & $50,00 \mathrm{~mm}$ \\
\hline Área Inicial da Amostra & $121,0 \mathrm{~mm}$ & $51,53 \mathrm{~mm}$ & $52,36 \mathrm{~mm}$ \\
\hline Área Final da Amostra & $120,2 \mathrm{~mm}$ & $120,6 \mathrm{~mm}$ & $121,0 \mathrm{~mm}$ \\
\hline
\end{tabular}

Tabela 3. Dimensões Corpo de Prova Ensaio de Charpy

\begin{tabular}{c|c|c|c}
\hline Amostra 1 & CP1 & CP2 & CP3 \\
\hline Formato da Amostra & Quadrado & Quadrado & Quadrado \\
\hline Material & ADI & ADI & ADI \\
\hline Lado 1 & $10,286 \mathrm{~mm}$ & $10,170 \mathrm{~mm}$ & $10,262 \mathrm{~mm}$ \\
\hline Lado 2 & $9,913 \mathrm{~mm}$ & $10,192 \mathrm{~mm}$ & $10,460 \mathrm{~mm}$ \\
\hline Comprimento & $55,95 \mathrm{~mm}$ & $54,30 \mathrm{~mm}$ & $55,73 \mathrm{~mm}$ \\
\hline Temperatura & $20^{\circ} \mathrm{C}$ & $20^{\circ} \mathrm{C}$ & $20^{\circ} \mathrm{C}$ \\
\hline
\end{tabular}

CP- Corpo de Prova

Tabela 4. Dimensões Corpo de Prova Ensaio de Charpy

\begin{tabular}{c|c|c|c}
\hline Amostra 2 & CP1 & CP2 & CP3 \\
\hline $\begin{array}{c}\text { Formato da } \\
\text { Amostra }\end{array}$ & Quadrado & Quadrado & Quadrado \\
\hline Material & ADI & ADI & ADI \\
\hline Lado 1 & $10,216 \mathrm{~mm}$ & $10,429 \mathrm{~mm}$ & $10,176 \mathrm{~mm}$ \\
\hline Lado 2 & $10,123 \mathrm{~mm}$ & $10,304 \mathrm{~mm}$ & $10,242 \mathrm{~mm}$ \\
\hline Comprimento & $56,19 \mathrm{~mm}$ & $55,79 \mathrm{~mm}$ & $54,72 \mathrm{~mm}$ \\
\hline Temperatura & $20^{\circ} \mathrm{C}$ & $20^{\circ} \mathrm{C}$ & $20^{\circ} \mathrm{C}$ \\
\hline
\end{tabular}


Tabela 5. Dimensões Corpo de Prova Ensaio de Charpy

\begin{tabular}{c|c|c|c}
\hline Amostra 3 & CP1 & CP2 & CP3 \\
\hline Formato da Amostra & Quadrado & Quadrado & Quadrado \\
\hline Material & ADI & ADI & ADI \\
\hline Lado 1 & $10,201 \mathrm{~mm}$ & $10,486 \mathrm{~mm}$ & $10,430 \mathrm{~mm}$ \\
\hline Lado 2 & $10,208 \mathrm{~mm}$ & $10,489 \mathrm{~mm}$ & $10,212 \mathrm{~mm}$ \\
\hline Comprimento & $55,01 \mathrm{~mm}$ & $55,03 \mathrm{~mm}$ & $54,74 \mathrm{~mm}$ \\
\hline Temperatura & $20^{\circ} \mathrm{C}$ & $20^{\circ} \mathrm{C}$ & $20^{\circ} \mathrm{C}$ \\
\hline
\end{tabular}

Tabela 6. Norma A897M Standard Specification for Austempered Ductile Iron Castings

\begin{tabular}{c|c}
\hline Grau & $1400 / 1100 / 1$ \\
\hline Resistência à tração & $\geq 1400 \mathrm{MPa}$ \\
\hline Limite de escoamento & $\leq 1100 \mathrm{MPa}$ \\
\hline Energia de Impacto & $\leq 35 \mathrm{~J}$ \\
\hline Alongamento & $1 \%$ \\
\hline Brinell Hardness & $\leq 380 \geq 477$ \\
\hline
\end{tabular}

Fonte: Norma ASTM A897/A897M - 06 (Reapproved 2011) - Standard Specification for Austempered Ductile Iron Castings.

Tabela 7. Resultado Ensaio de Tração

\begin{tabular}{c|c|c|c}
\hline Amostra & $\mathbf{1}$ & $\mathbf{2}$ & $\mathbf{3}$ \\
\hline Resistência à tração & $1372 \mathrm{MPa}$ & $1387 \mathrm{MPa}$ & $1359 \mathrm{MPa}$ \\
\hline Limite de Escoamento & $1241 \mathrm{MPa}$ & $1189 \mathrm{MPa}$ & $1147 \mathrm{MPa}$ \\
\hline Alongamento & $\geq 1 \%$ & $\geq 3 \%$ & $\geq 5 \%$ \\
\hline
\end{tabular}


Tabela 8. Ensaio de Impacto Charpy e Dureza Brinell

\begin{tabular}{c|c|c|c}
\hline Amostra 1 & CP1 & CP2 & CP3 \\
\hline Tipo de Entalhe & Sem Entalhe & Sem Entalhe & Sem Entalhe \\
\hline Energia Potencial & $30 \mathrm{kpm}$ & $30 \mathrm{kpm}$ & $30 \mathrm{kpm}$ \\
\hline Energia Absorvida & $23,5 \mathrm{~J}$ & $33,3 \mathrm{~J}$ & $23,5 \mathrm{~J}$ \\
\hline Média de Energia & & $26,8 \mathrm{~J}$ & \\
\hline Dureza Brinell Média & $381 \mathrm{HB}$ & $381 \mathrm{HB}$ & $371 \mathrm{HB}$ \\
\hline
\end{tabular}

$1 \mathrm{kpm}=9,79278 \mathrm{~J}$

Tabela 9. Ensaio de Impacto Charpy e Dureza Brinell

\begin{tabular}{c|c|c|c}
\hline Amostra 2 & CP1 & CP2 & CP3 \\
\hline Tipo de Entalhe & Sem Entalhe & Sem Entalhe & Sem Entalhe \\
\hline Energia Potencial & $30 \mathrm{kpm}$ & $30 \mathrm{kpm}$ & $30 \mathrm{kpm}$ \\
\hline Energia Absorvida & $47,0 \mathrm{~J}$ & $72,5 \mathrm{~J}$ & $68,5 \mathrm{~J}$ \\
\hline Média de Energia & & $62,7 \mathrm{~J}$ & \\
\hline Dureza Brinell Média & $415 \mathrm{HB}$ & $405 \mathrm{HB}$ & $415 \mathrm{HB}$ \\
\hline
\end{tabular}

Tabela 10. Ensaio de Impacto Charpy e Dureza Brinell

\begin{tabular}{c|c|c|c}
\hline Amostra 3 & CP1 & CP2 & CP3 \\
\hline Tipo de Entalhe & Sem Entalhe & Sem Entalhe & Sem Entalhe \\
\hline Energia Potencial & $30 \mathrm{kpm}$ & $30 \mathrm{kpm}$ & $30 \mathrm{kpm}$ \\
\hline Energia Absorvida & $72,5 \mathrm{~J}$ & $74,4 \mathrm{~J}$ & $76,4 \mathrm{~J}$ \\
\hline Média de Energia & & $74,4 \mathrm{~J}$ & \\
\hline Dureza Brinell Média & $390 \mathrm{HB}$ & $400 \mathrm{HB}$ & $390 \mathrm{HB}$ \\
\hline
\end{tabular}


Tabela 11. Resultados - Corpos de Prova.

\begin{tabular}{c|c|c|c}
\hline & Corpo de Prova & Dureza Brinell & Ensaio de Impacto Charpy \\
\hline \multirow{4}{*}{$\begin{array}{c}\text { Amostra } \\
\mathbf{1}\end{array}$} & 1 & Sim & Não \\
\cline { 2 - 4 } & 2 & Sim & Não \\
\hline \multirow{2}{*}{$\begin{array}{c}\text { Amostra } \\
\mathbf{2}\end{array}$} & 3 & Não & Não \\
\cline { 2 - 4 } & 1 & Sim & Sim \\
\hline \multirow{2}{*}{$\begin{array}{c}\text { Amostra } \\
\mathbf{3}\end{array}$} & 2 & Sim & Sim \\
\cline { 2 - 4 } & 3 & Sim & Sim \\
\cline { 2 - 4 } & 2 & SIm & Sim \\
\hline
\end{tabular}

PERIÓDICO TCHÊ QUÍMICA • www.periodico.tchequimica.com • Vol. 6 N. 12.

• ISSN 1806-0374 (impresso) • ISSN 1806-9827 (CD-ROM)・ISSN 2179-0302 (meio eletrônico)

The Periódico Tchê Química (ISSN: 1806-0374; 2179-0302) is an open-access journal since 2004. Journal DOI: 10.52571/PTQ. http://www.tchequimica.com. This text was introduced in this file in 2021 for compliance reasons.

(0) The Author(s)

OPEN ACCESS. This article is licensed under a Creative Commons Attribution 4.0 (CC BY 4.0) International License, which permits use, sharing, adaptation, distribution, and reproduction in any medium or format, as long as you give appropriate credit to the original author(s) and the source, provide a link to the Creative Commons license, and indicate if changes were made. The images or other third-party material in this article are included in the article 's Creative Commons license unless indicated otherwise in a credit line to the material . If material is not included in the article's Creative Commons license and your intended use is not permitted by statutory regulation or exceeds the permitted use, you will need to obtain permission directly from the copyright holder. To view a copy of this license, visit http://creativecommons.org/licenses/by/4.0/. 